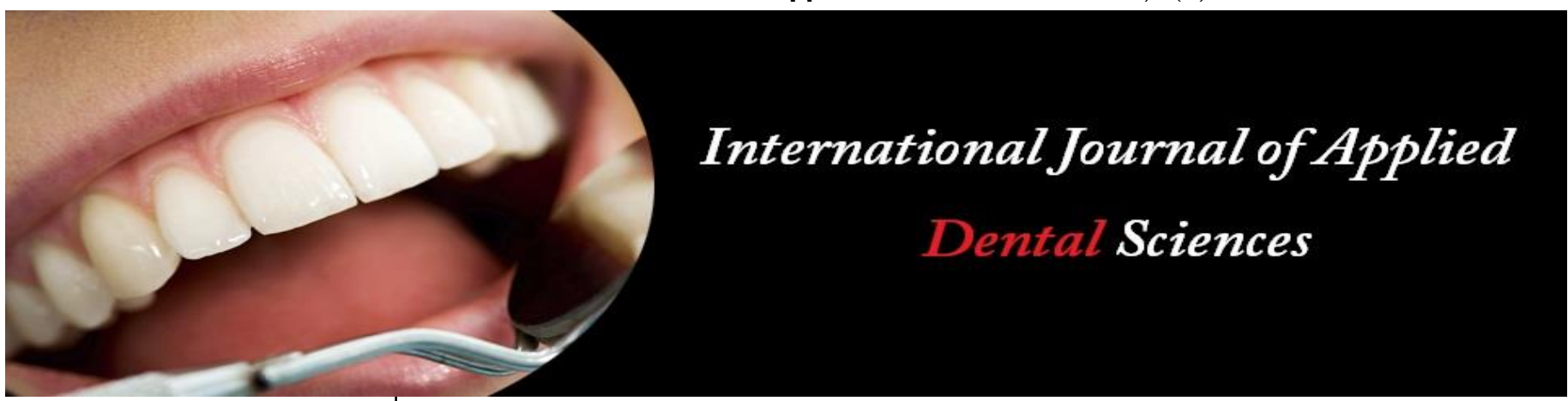

ISSN Print: 2394-7489

ISSN Online: 2394-7497

IJADS 2021; 7(2): 496-502

(C) 2021 IJADS

www.oraljournal.com

Received: 07-02-2021

Accepted: 09-03-2021

Dr. Yogesh Kumar

Post-Graduate Student,

Department of Oral and

Maxillofacial Surgery, Subharti

Dental College \& Hospital,

Swami Vivekanand Subharti

University, Meerut,

Uttar Pradesh, India

Dr. Vishal Bansal

Professor and Head, Department

of Oral and Maxillofacial

Surgery, Subharti Dental College

\& Hospital, Swami Vivekanand

Subharti University, Meerut,

Uttar Pradesh, India

Dr. Prajesh Dubey

Professor, Department of Oral

and Maxillofacial Surgery,

Subharti Dental College \&

Hospital, Swami Vivekanand

Subharti University, Meerut,

Uttar Pradesh, India
Corresponding Author:

Dr. Yogesh Kumar

Post-Graduate Student,

Department of Oral and

Maxillofacial Surgery, Subharti

Dental College \& Hospital,

Swami Vivekanand Subharti

University, Meerut,

Uttar Pradesh, India

\section{Evaluation of bone gain and implant survival after vertical and horizontal ridge augmentation using titanium mesh with simultaneous implant placement in deficient maxillary and mandibular ridge: $A$ prospective clinical study}

\author{
Dr. Yogesh Kumar, Dr. Vishal Bansal and Dr. Prajesh Dubey
}

DOI: https://doi.org/10.22271/oral.2021.v7.i2h.1252

\section{Abstract}

The present clinical study was conducted with a one-stage approach for alveolar ridge augmentation using titanium mesh with simultaneous implant placement in the compromised ridges. This prospective study included a total no. of 26 partially edentulous sites which were treated with implants and simultaneous guided bone regeneration with titanium mesh. We found a significant increase in the buccolingual width at implant site when comparison was made at different time intervals. We found a significant decrease in the mean bone density on the mesial side (1934.62 \pm 598.26 gray units), while no significant decrease in the mean bone density was found on the distal side ( $1873 \pm 576.12$ gray units) when compared at immediate post-operative and 6-months post-operative time interval. Despite the use of micropore titanium mesh, we have noticed membrane exposure in 10 patients $(71.42 \%)$ among 14 patients which resulted in detrimental influence on the amount of bone augmentation. The bucco-lingual width of the alveolar crest has been significantly increased, but we couldn't achieve any optimal gain in alveolar crest height.

Keywords: GBR, alveolar ridge augmentation, titanium mesh, one-stage approach, PRF, xenografts

\section{Introduction}

Dental rehabilitation with osseo integrated dental implant is a treatment of choice among patients suffering from tooth loss as it avoid cutting of adjacent normal or sound tooth structure with predictable long-term prognosis. Adequate alveolar bone is important not only for the prosthesis' aesthetic appearance, but also for its biomechanical support. However, presence of alveolar ridge deficiency, anatomic constraints preclude the placement of normal sized dental implants ${ }^{[1]}$. To counteract these problems, several bone regenerative surgical techniques (additive, distraction, expansion) with adjuvant measures (PRF, barrier membranes, growth factors) are available with their own advantages and limitations ${ }^{[2-7]}$. Graft materials such as autologous, homologous, heterologous and synthetic bone are used singly or in combination. Autologous bone $(\mathrm{AB})$ graft is considered the "gold standard" due to its high biocompatibility, osteoinductive, osteoconductive and osteogenic ability, but the limited availability of intraoral sites and the donor site morbidity has restricted its use. In the literature, the anorganic bovine bone $(\mathrm{ABB})$ has revealed a long-term success in ridge augmentation technique as it possesses fundamental characteristics of biocompatibility and osteoconductivity ${ }^{[8,9]}$. It produces a good scaffold for new bone formation and hence it is being widely used for vertical and horizontal augmentation, sinus lift procedure and socket preservation ${ }^{[10-12]}$. The purpose of the present prospective clinical study is to evaluate the implant stability, horizontal and vertical bone gain after ridge augmentation with xenografts in the patients treated with titanium meshes positioned simultaneously with dental implants fixed over them. 


\section{Material and Method}

This prospective study included a total no. of 14 patients in whom implants were placed at 26 sites with deficient alveolar volume using one-stage approach within anatomic constraints areas. All the patients were healthy with minor medical comorbidities. Ethical clearance and written consent was obtained. For all the patients a careful clinical and radiographic analysis was performed pre-operatively and surgical stents was fabricated for ease in implant placement.

\section{Surgical Technique}

Under aseptic condition, full thickness quadrangular mucoperiosteal flap was raised to expose the implant site after administering local anesthesia. Then osteotomy was performed, starting with a lance drill and then using consecutive drills to achieve the desired diameter and length for implant placement. The implant shoulder was positioned above the level of the adjacent teeth with a minimum of two threads exposed. The vertical dimension of the exposed implant surface was measured with a Michigan periodontal probe. The stability of the implant was determined clinically by the removal of implant driver. Alveolar decortication was performed around the graft recipient area. Hydroxyapatite and anorganic bovine bone (xenograft) was carefully packed around the exposed threads and nearby area. $0.07 \mathrm{~mm}$ thickness micropore titanium mesh was adjusted according to the individual anatomy, modelled and finally secured with the titanium screws over the grafted site. An absorbable membrane of PRF was adapted over the titanium mesh to prevent soft tissue dehiscence. Closure of the surgical site was then performed with 3-0 vicryl suture material. Patients were kept on oral antibiotics and analgesics for 5 days. All the patients were followed with a minimum period of 6-months and complications present were noted. Second-stage surgery was performed after 3-months followed by prosthetic rehabilitation. Radiographic assessment was made with the help of CBCT to evaluate overall changes in the bone height, quality, and quantity of the bone around the exposed threads of the implant at pre-operative, immediate post-operative, and 6-months postoperative follow-up period in all the patients. (figure: 1,2a, 2b,2c,3a,3b,3c)

\section{Statistical Analysis}

The data was entered in microsoft excel format and was analyzed using SPSS version 21(IBM SPSS Corp. Ltd. Armonk, N.Y).The continuous data was represented as mean \pm S.D. Bivariate analysis was done using Paired $t$ test. $P$ value $<0.05$ was considered as significant.

\section{Results}

The study included 26 implant sites in 14 patients, among which 10 were males and 4 females with age range between 18-42 years (mean age 32 years) at the time of implant placement. (Table:1, graph 1,2,3) From pre-operative CBCT scan analysis it was confirmed that the ridge was too narrow for the placement of conventional implant diameter as shown in pre-operative CBCT. In this study, the minimum implant dimensions used was $3.75 \times 8 \mathrm{~mm}$. We found a significant increase in the bucco-lingual width at implant site from preoperative to immediate post-operative time interval, immediate post-operative to 6-months post-operative time interval and from pre-operative to 6-months post-operative time interval. (Table:2,graph:4) Height of the alveolar crest was measured on the proximal sites of exposed implant threads. We found no significant difference in the mean alveolar crestal height level when comparison was made at different time intervals. (Table:3, graph:5) We found a significant decrease in the mean bone density on the mesial side, while no significant decrease in the mean bone density was found on the distal side when compared at immediate post-operative and 6-months post-operative time interval. Hence, these results showed the failure of graft integration with the native bone more on the mesial side as compared to distal side. (Table:4, graph 6) Mesh exposure was seen in 10 patients among 14 patients. This mesh exposure was seen on lingual aspect in 2 patients, on buccal aspect in 2 patient and on occlusal aspect in 6 patients. (Table:5)

Table 1: Demographic data depicting the total no. of patients, age, gender, and site of implant placement.

\begin{tabular}{|c|c|c|c|}
\hline Patient & Age & Gender & Implant Site (Tooth number*) \\
\hline 1 & 41years & Male & $\begin{array}{l}35 \\
36 \\
45 \\
47\end{array}$ \\
\hline 2 & 35years & Male & 35 \\
\hline 3 & 18years & Female & $\begin{array}{l}24 \\
25\end{array}$ \\
\hline 4 & 42years & Male & 26 \\
\hline 5 & 23years & Male & $\begin{array}{l}35 \\
36 \\
37\end{array}$ \\
\hline 6 & 41years & Male & 37 \\
\hline 7 & 30years & Female & 16 \\
\hline 8 & 18years & Male & 36 \\
\hline 9 & 42years & Female & 27 \\
\hline 10 & 32years & Male & $\begin{array}{l}35 \\
36 \\
45 \\
47\end{array}$ \\
\hline 11 & 24years & Female & 24 \\
\hline 12 & 40years & Male & 26 \\
\hline 13 & 42years & Male & $\begin{array}{l}45 \\
46 \\
47\end{array}$ \\
\hline 14 & 35years & Male & $\begin{array}{l}24 \\
25\end{array}$ \\
\hline
\end{tabular}

*(Tooth no. $=$ according to FDI tooth numbering system $)$

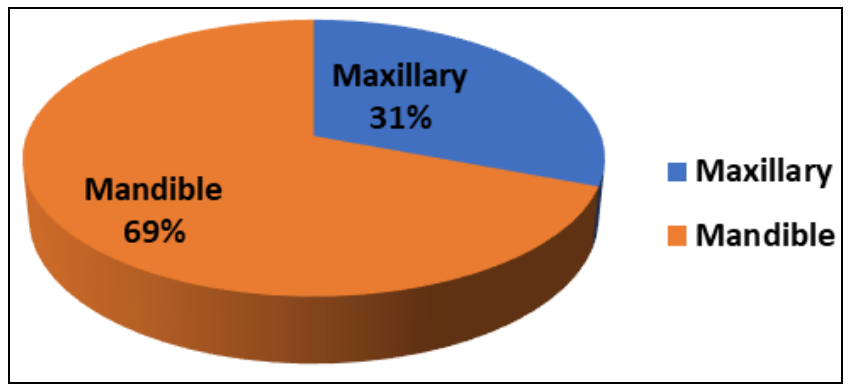

Graph 1: Distribution according to sites 


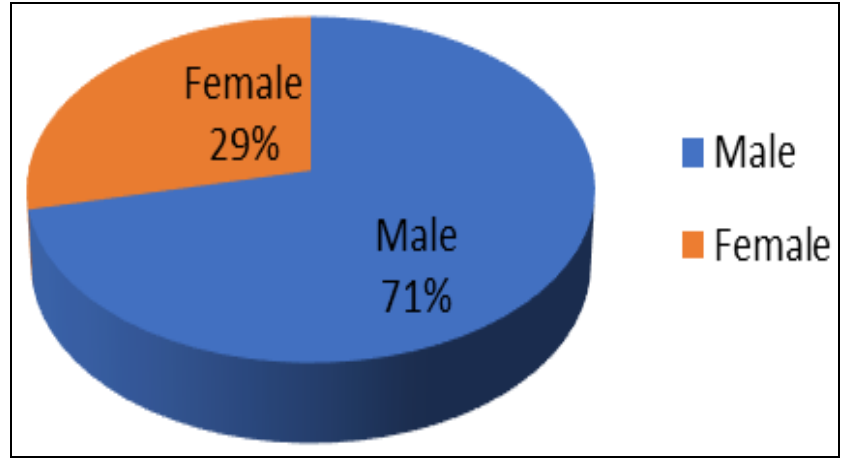

Graph 2: Gender wise distribution

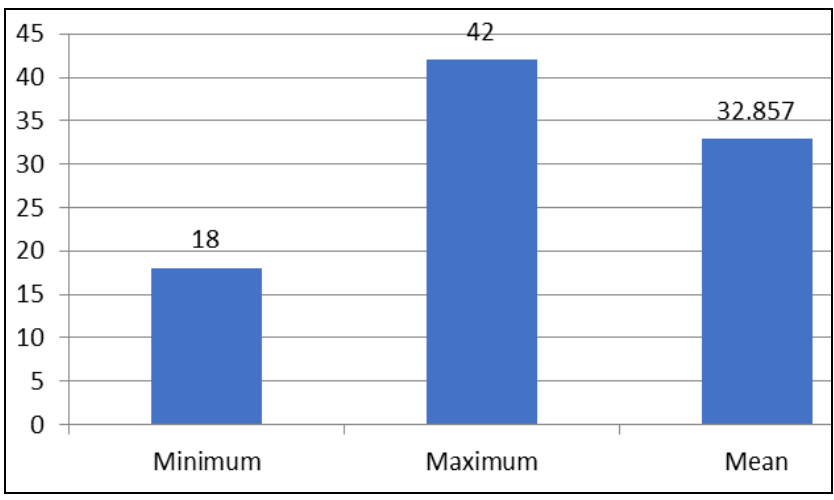

Graph 3: Mean age (in years)

Table 2: Comparison of buccolingual width at different time intervals (in $\mathrm{mm}$ )

\begin{tabular}{|c|c|c|c|c|c|c|c|}
\hline & Mean & $\mathbf{N}$ & Std. Deviation & \begin{tabular}{|l|} 
Std. Error Mean \\
\end{tabular} & Mean difference & Std dev & P value \\
\hline PREOP & 5.1331 & 26 & 1.75685 & .48726 & \multirow{2}{*}{-1.20923} & \multirow{2}{*}{1.85956} & \multirow{2}{*}{0.037} \\
\hline Immediately after implant placement & 6.3423 & 26 & 2.08207 & .57746 & & & \\
\hline Immediately after implant placement & 6.3423 & 26 & 2.08207 & .57746 & \multirow{2}{*}{-1.31769} & \multirow{2}{*}{1.06311} & \multirow{2}{*}{0.001} \\
\hline After 6 months & 7.6600 & 26 & 2.31054 & .64083 & & & \\
\hline PREOP & 5.1331 & 26 & 1.75685 & .48726 & \multirow{2}{*}{-2.52692} & \multirow{2}{*}{2.14141} & \multirow{2}{*}{0.001} \\
\hline & After 6 months 7.6600 & 26 & 2.31054 & .64083 & & & \\
\hline
\end{tabular}

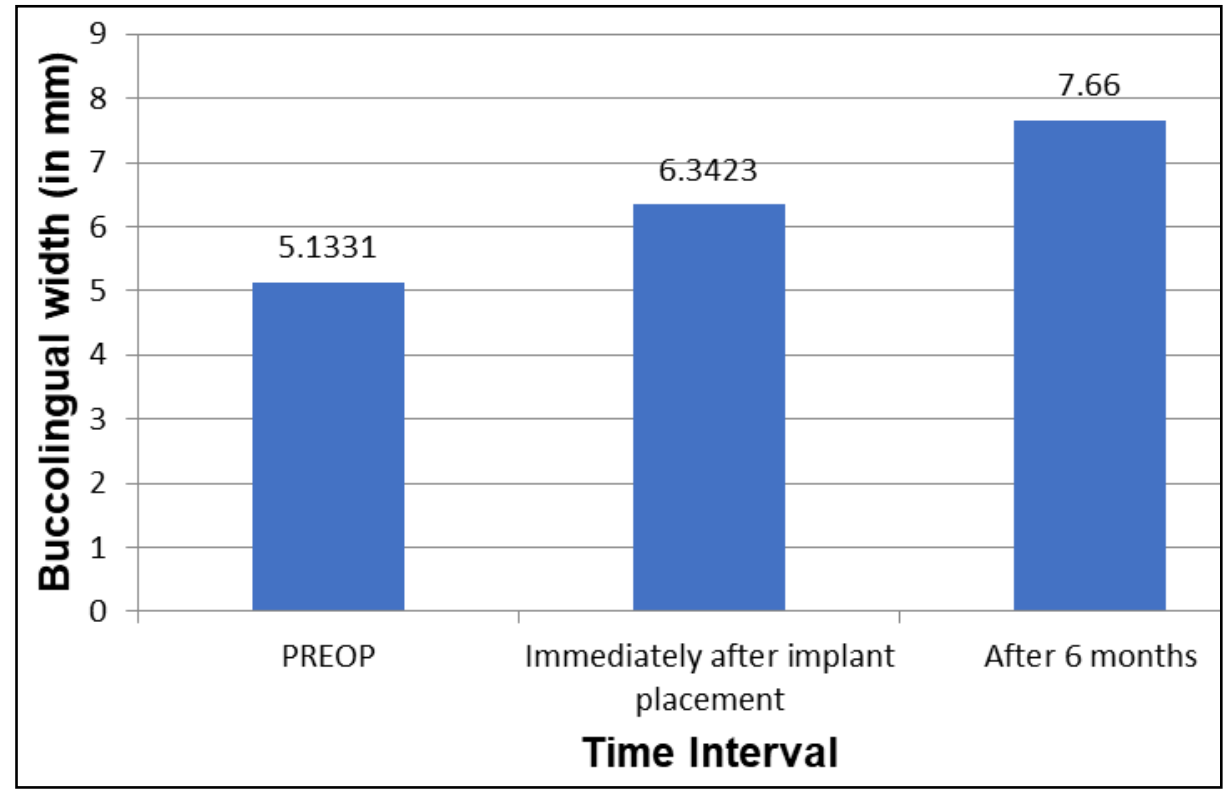

Graph 4: Buccolingual width (in $\mathrm{mm}$ )

Table 3: Mean alveolar crestal height level (in $\mathrm{mm}$ )

\begin{tabular}{|c|c|c|c|c|c|c|c|}
\hline & & \begin{tabular}{|l|l} 
Mean & 1 \\
\end{tabular} & \begin{tabular}{l|l|}
$\mathbf{N}$ & Std. Deviation \\
\end{tabular} & Std. Error Mean & Mean difference & Std dev & P value \\
\hline \multirow{2}{*}{ Mesial } & Immediately after implant placement & \begin{tabular}{|l|l|}
2.0092 & 2 \\
\end{tabular} & 1.63995 & .45484 & \multirow{2}{*}{-.69000} & \multirow{2}{*}{1.33570} & \multirow{2}{*}{. 087} \\
\hline & At 6 months & \begin{tabular}{|l|l|l|}
2.6992 \\
\end{tabular} & 1.69681 & .47061 & & & \\
\hline \multirow{2}{*}{ Distal } & Immediately after implant placement & 2.93922 & 1.88333 & .52234 & \multirow{2}{*}{-.64692} & \multirow{2}{*}{2.12994} & \multirow{2}{*}{.295} \\
\hline & At 6 months & 3.58622 & 2.33142 & .64662 & & & \\
\hline
\end{tabular}




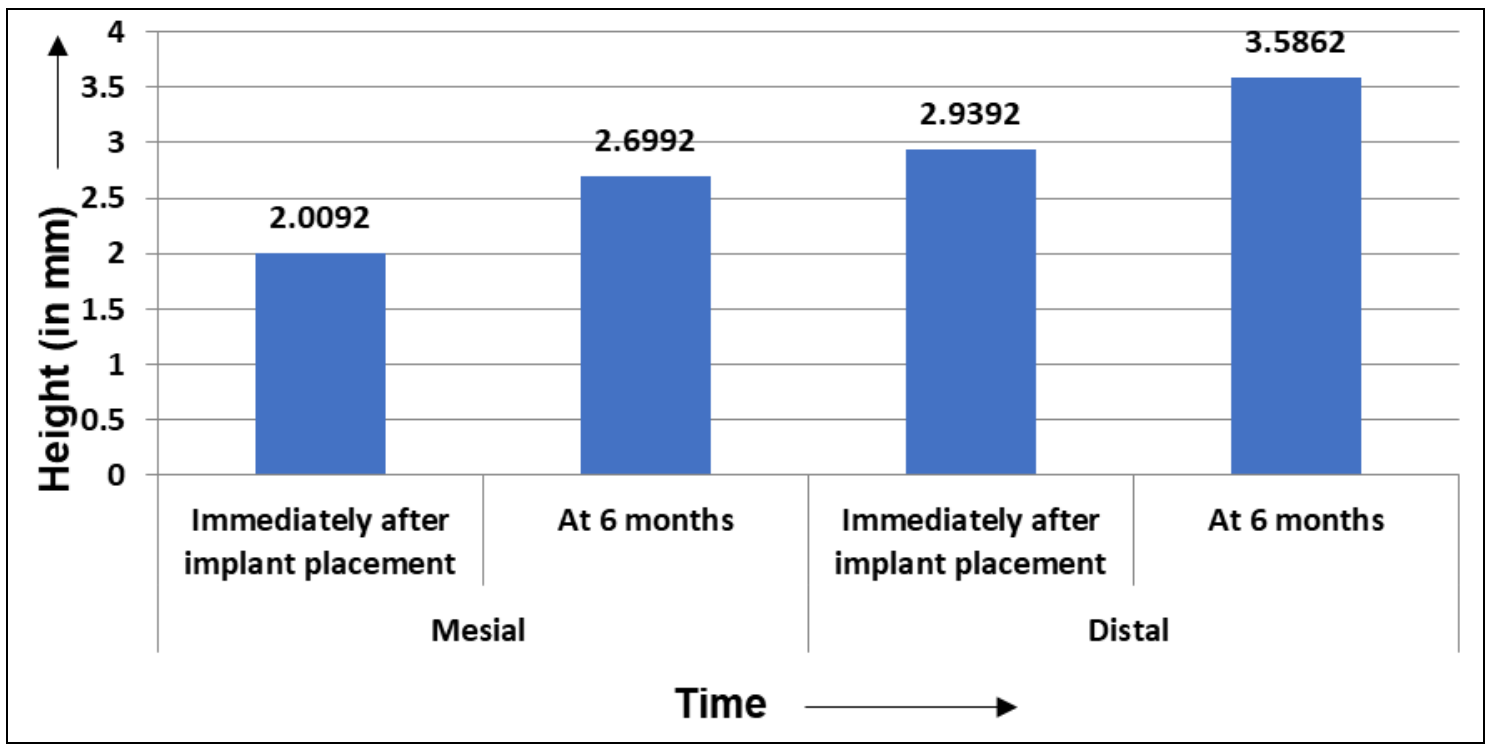

Graph 5: Mean alveolar crestal height level (in mm)

Table 4: Comparison of mean bone density (in Gray Scale)

\begin{tabular}{|c|c|c|c|c|c|c|c|c|}
\hline & & Mean & $\mathbf{N}$ & $\begin{array}{c}\text { Std. } \\
\text { Deviation }\end{array}$ & $\begin{array}{c}\text { Std. Error } \\
\text { Mean }\end{array}$ & $\begin{array}{c}\text { Mean } \\
\text { difference }\end{array}$ & Std dev & $\begin{array}{c}\mathbf{P} \\
\text { value }\end{array}$ \\
\hline \multirow{2}{*}{ Mesial } & Immediately after implant placement & 1934.62 & 26 & 447.858 & 124.214 & \multirow{2}{*}{650.00000} & \multirow{2}{*}{598.26137} & \multirow{2}{*}{0.002} \\
\hline & At 6 months & 1284.6154 & 26 & 483.21174 & 134.01882 & & & \\
\hline \multirow{2}{*}{ Distal } & Immediately after implant placement & 1873.08 & 26 & 319.254 & 88.545 & \multirow{2}{*}{23.07692} & \multirow{2}{*}{576.12766} & \multirow{2}{*}{0.888} \\
\hline & At 6 months & 1850.0000 & 26 & 697.01746 & 193.31786 & & & \\
\hline
\end{tabular}

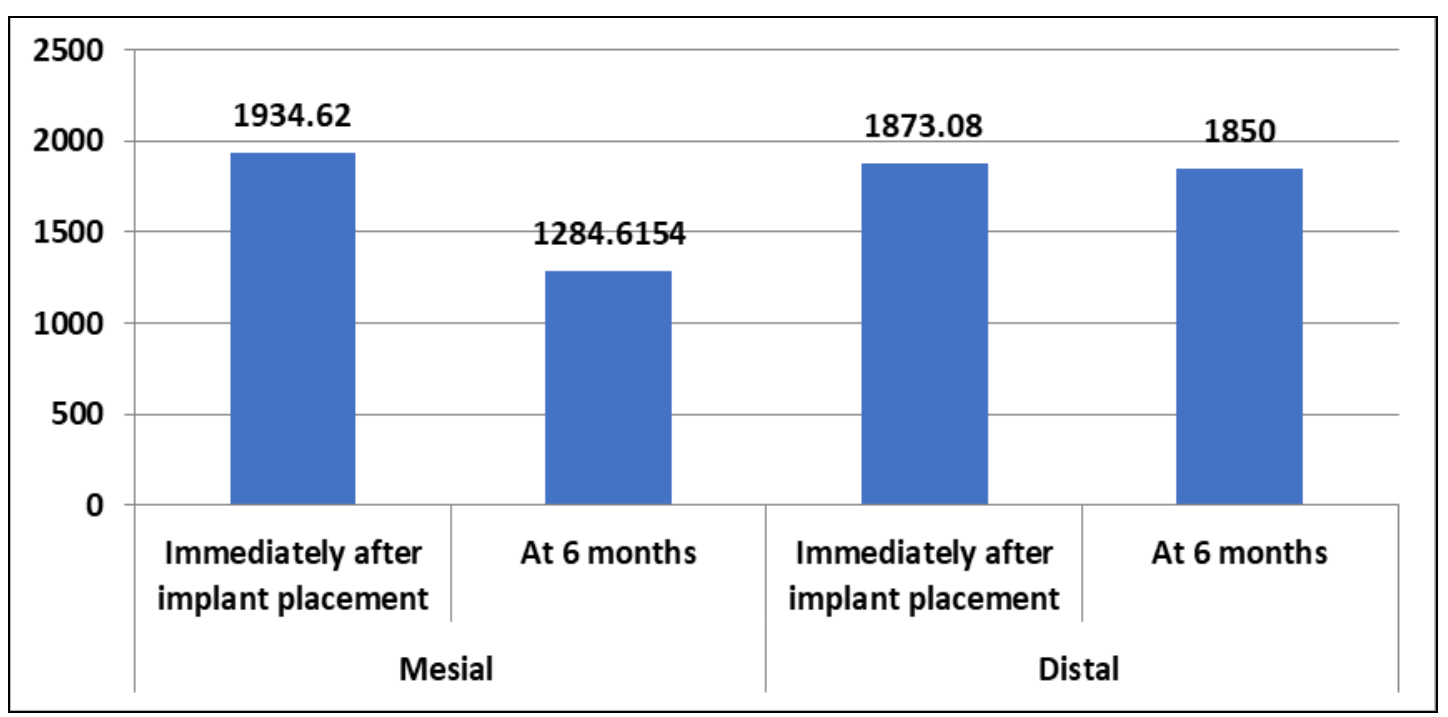

Graph 6: Bone density ( in Gray Scale)

Table 5: Data depicting mesh exposure

\begin{tabular}{|c|c|c|}
\hline & $\mathrm{N}$ & $\%$ \\
\hline Mesh exposure & 10 & $71.42 \%$ \\
\hline \multicolumn{2}{|c|}{ Area of Exposure } \\
\hline Lingual & 2 & $14.28 \%$ \\
\hline Buccal & 2 & $14.28 \%$ \\
\hline Occlusal & 6 & $42.85 \%$ \\
\hline
\end{tabular}




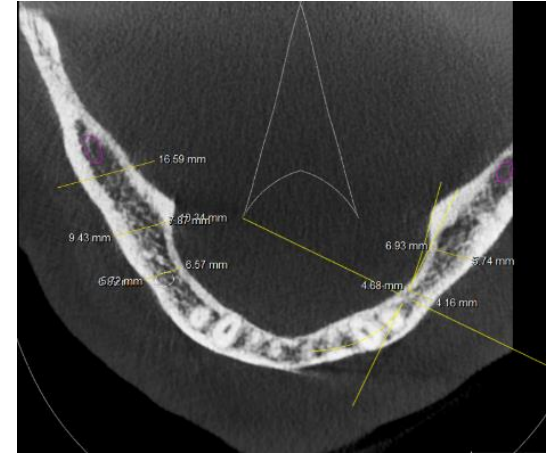

Fig 1: Pre-operative CBCT showing narrow ridge

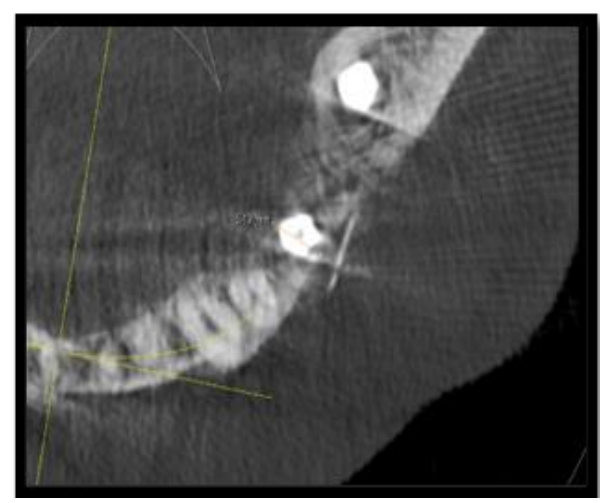

a.

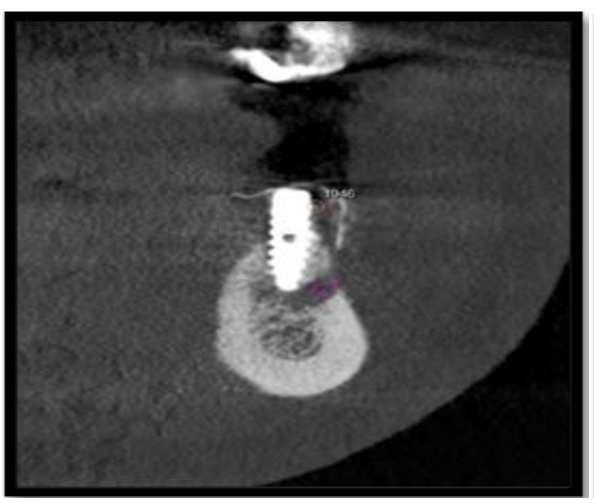

b.

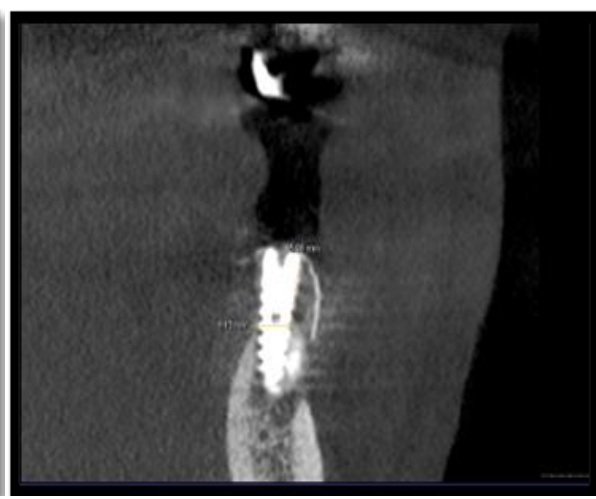

Fig 2: Immediate post-operative CBCTs: a) Bone width (in $\mathrm{mm}$ ) b) Bone quality (in Gray Scale) c) Bone height (in mm)

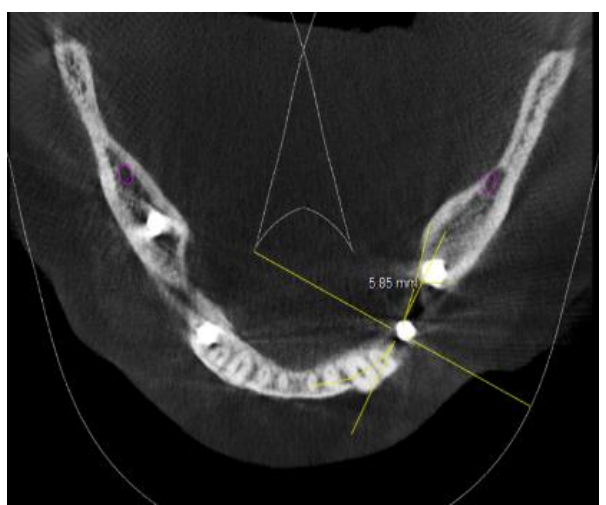

a.

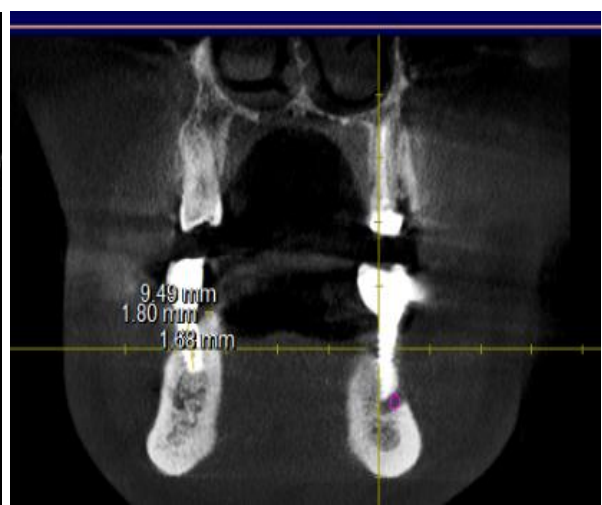

b.

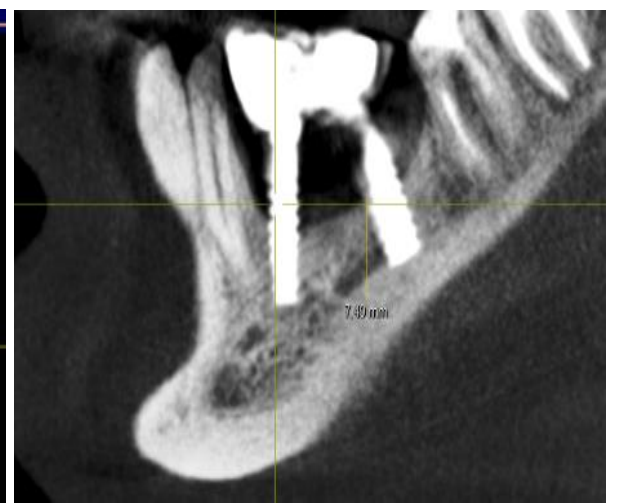

c.

Fig 3: 6-months post-operative CBCTs: a) Bone width (in $\mathrm{mm}$ ) b) Bone quality (in Gray Scale) c) Bone height (in $\mathrm{mm}$ )

\section{Discussion}

The pneumatized sinus, inferior alveolar nerve, mental foramen, and lingual concavity are all anatomical limitations and essential structures that prohibit the placement of long dental implants in atrophic maxilla and mandible ${ }^{[13]}$. Traditional onlay/inlay grafts, interpositional sandwich osteotomies, directed bone regeneration with semipermeable membranes, piezoelectric stimulation, and alveolar distraction osteogenesis procedures have all been established to prevent these problems ${ }^{[14]}$. Since the graft materials can be retained in the sinus with ample blood supply from the alveolar bone and sinus membrane, the sinus lift procedure at the posterior maxilla is more predictable than other vertical augmentation procedures ${ }^{[15]}$. Extra augmentation procedures, on the other hand, often lift the cost, morbidity, and treatment time. Sinus membrane perforation was the most common surgical complication (prevalence ranged from 0 to 21.4 percent, with a mean of 3.8 percent), and sinus infection was the most common postoperative complication, according to a systematic study of trans-alveolar sinus raise (prevalence varied between 0 and 2.5 percent, with a mean of 0.8 percent) [16]. Membrane perforation was found to be 19.5 percent (range 0-58.3 percent) and sinus infection was found to be 2.9 percent (range 0-7.4 percent) in patients who underwent a lateral approach. Hemorrhage, nasal bleeding, a blocked nose, and hematomas are also potential complications after surgery [15].

Due to mandibular bone atrophy, the inferior alveolar nerve (IAN) is more vulnerable to invasion during implant site preparation and placement. Dental implants were discovered to be the most common etiological risk factor for nerve injury $(56.3 \%)^{[19]}$.

Short implants are one of the treatment of choice among different alternative (basal, zygomatic and pterygoid implants) in such situations as it is less invasive and require less exposure. Nonetheless, the long-term feasibility of short dental implants has been a contentious issue. Papaspyridakos ${ }^{[20]}$ in their study indicated that survival rates of short implants 
( $\leq 6 \mathrm{~mm}$ ) ranged from $86.7 \%$ to $100 \%$, whereas the survival rates for longer implants (>6 mm) were $95 \%$ to $100 \%$ with a follow-up from 1 to 5 years. Short implants were found to have a lower implant survival rate than longer implants. The use of short implants has been challenged due to an unfavorable mechanical force distribution caused by a high crown-to-implant ratio and higher crestal bone strains surrounding short implants as compared to long implants, which has been potentially linked to crestal bone loss [21], Renouard ${ }^{[23]}$ et al. recorded $0.440 .52 \mathrm{~mm}$ bone resorption of 96 short implants after two years in 2005.

The one-stage approach, which involves using grafting material with or without membranes at the time of implant placement, reduces the overall treatment time ${ }^{[24]}$. Bone regeneration (GBR) utilizing this one-stage procedure around submerged implants has been successful both in humans and animals ${ }^{[25,26]}$ It has been shown that the exposed implant threads are slowly covered with bone through regeneration. Cochran \& Douglas (1993) ${ }^{[27]}$ were the first to describe the possibility of regenerating bone around one-stage implants using a non-submerged approach.

In present study, we found a significant increase in the buccolingual width at implant site from pre-operative to immediate post-operative time interval $(5.13 \pm 1.85 \mathrm{~mm})$, immediate post-operative to 6-months post-operative time interval $(6.34$ $\pm 1.06 \mathrm{~mm})$ and from pre-operative to 6-months postoperative time interval $(5.13 \pm 2.14 \mathrm{~mm})$. These results favors the horizontal augmentation that has occurred in this study.

Various authors have discussed the success criteria of dental implants on the basis of crestal bone loss. P. Papaspyridakos et al in $2011^{[20]}$ examined most frequently used criteria to define treatment success in implant dentistry. It was reported that bone loss at 1 st year $<1.5 \mathrm{~mm}$ and annual bone loss $<0.2$ $\mathrm{mm}$ thereafter was considered to be most acceptable criteria for success of dental implants. In the present study, height of the alveolar crest was measured on the proximal sites of exposed implant threads. In this study, we found a decrease in the height of alveolar crest which was not significant when comparison was made between immediate post-operative and 6-months post-operative time interval both on the mesial $(2.00 \pm 1.33 \mathrm{~mm})$ and distal aspect $(2.93 \pm 2.12 \mathrm{~mm})$.

Four basic principles must be followed throughout the surgery and during the healing process for GBR procedures to be effective which are primary closure, angiogenesis, space maintenance, and stability of the wound, the so-called PASS principle ${ }^{[28]}$. Complications with any of these principles can result in premature membrane exposure that potentially compromises the regenerative process. Her et al. (2010) [29] conducted a study and found mesh exposure in 7 patients (26\%) out of 27 augmented sites. In this study, despite the use of micropore titanium mesh, we have noticed mesh exposure in 10 patients $(71.42 \%)$ among 14 patients. Out of 10 , mesh exposure was seen on lingual aspect in 2 patient (14.28\%), on buccal aspect in 2 patient $(14.28 \%)$ and on occlusal aspect in 6 patients $(42.85 \%)$ which was quite high which could be a possible explanation for detrimental influence on the amount of bone augmentation in this study.

\section{Conclusion}

The present clinical study was conducted with a one-stage approach for alveolar ridge augmentation using titanium mesh with simultaneous implant placement in the compromised ridges. Despite the use of micropore titanium mesh along with PRF coverage over it we have found a higher rate of membrane exposure in the early healing phase period. This could probably be the main reason behind the high amount of graft resorption that was observed in the present study. We were able to achieve a significant increase the bucco-lingual width of the alveolar crest but failed to achieve any optimal gain in alveolar crest height. Future studies investigating the impact of membrane exposure using one-stage approach in compromised ridges are needed.
Abbreviations
GBR - Guided Bone Regeneration
PRF - Platelet Rich Fibrin
AB - Anorganic Bovine
ABB- Anorganic Bovine Bone
CBCT- Cone Beam Computed Tomography
IAN - Inferior Alveolar Nerve
PASS - Primary wound closure, Angiogenesis, Space maintenance, and Stability of the blood clot
SD - Standard Deviation

\section{References}

1. Misch CE. Contemporary implant dentistry. St. Louis: Mosby-Year Book 1993, 427-31.

2. Bottino MC, Thomas V, Schmidt G, Vohra YK, Chu TM, Kowolik MJ et al. Recent advances in the development of GTR/GBR membranes for periodontal regeneration-a materials perspective. Dent Mater 2012;28(7):703-21.

3. Lee HG, Kim YD. Volumetric stability of autogenous bone graft with mandibular body bone: cone-beam computed tomography and three-dimensional reconstruction analysis. J Korean Assoc Oral Maxillofac Surg 2015;41(5):232-9.

4. Jung RE, Fenner N, Hämmerle $\mathrm{CH}$, Zitzmann NU. Long-term outcome of implants placed with guided bone regeneration (GBR) using resorbable and non-resorbable membranes after 12-14 years. Clin Oral Implants Res. 2013;24(10):1065-73.

5. Bosshardt DD. The alveolar ridge splitting/expansion technique: a systematic review. Clin Oral Implants Res 2014;0:1-15

6. Simion M, Fontana F. Autogenous and xenogeneic bone grafts for the bone regeneration. A literature review. Minerva Stomatol 2004;53(5):191-206.

7. Dal Polo MR, Poli PP, Rancitelli D, Beretta M, Maiorana C. Alveolar ridge reconstruction with titanium meshes: a systematic review of the literature. Med Oral Patol Oral Cir Bucal 2014;19(6):639-46.

8. Von Arx T, Hardt N, Wallkamm B. The TIME technique: a new method for localized alveolar ridge augmentation prior to placement of dental implants. Int $\mathbf{J}$ Oral Maxillofac Implants 1996;11:387-394.

9. Hammerle $\mathrm{CH}$, Chiantella GC, Karring T, Lang NP. The effect of a deproteinized bovine bone material on bone regeneration around titanium dental implants. Clin Oral Implants Res 1998;9:151-162.

10. Piattelli M, Favero GA, Scarano A, Orsini G, Piattelli A. Bone reactions to anorganic bone (Bio-Oss) used in sinus augmentation procedures: a histologic long-term report of 20 cases in humans. Int $\mathbf{J}$ Oral Maxillofac Implants 1999; 14:835-840.

11. Zitzmann NU, Scharer P, Marinello CP, Schupbach P, Berglundh T. Alveolar ridge augmentation with Bio-Oss: a histologic study in humans. Int $\mathbf{J}$ Periodontics Restorative Dent 2001;21:288-295.

12. Fugazzotto PA. GBR using bovine bone matrix and resorbable a non-resorbable membranes. Part 1: 
histologic results. Int $\mathrm{J}$ Periodontics Restorative Dent 2003;23:361-369.

13. Chandra P, Govindaraju P, Chowdhary R. Radiographic evaluation of anatomical variables in maxilla and mandible in relation to dental implant placement. Indian J Dent Res 2016;27(4):344.

14. Scarano A, Sinjari B, Murmura G, Lorusso F. Neurosensory disturbance of the inferior alveolar nerve after 3025 implant placements. Implant Dent 2017;26:735-43.

15. Pjetursson BE, Tan WC, Zwahlen M, Lang NP. A systematic review of the success of sinus floor elevation and survival of implants inserted in combination with sinus floor elevation: part I: lateral approach. J Clin Periodontol 2008;35:216-40.

16. Tan WC, Lang NP, Zwahlen M, Pjetursson BE. A systematic review of the success of sinus floor elevation and survival of implants inserted in combination with sinus floor elevation Part II: transalveolar technique. J Clin Periodontol 2008;35:241-54.

17. Lin CS, Wu SY, Huang HY, Lai YL. Systematic review and meta-analysis on incidence of altered sensation of mandibular implant surgery. PLoS One 2016;11(4):0154082.

18. Başa O, Dilek OC. Assessment of the risk of perforation of the mandibular canal by implant drill using density and thickness parameters. J Gerodontol 2011;28(3):213-20.

19. Juodzbalys G, Wang HL, Sabalys G, Sidlauskas A, Galindo-Moreno P. Inferior alveolar nerve injury associated with implant surgery. Clin Oral Implants Res 2013;24(2):183-90.

20. Papaspyridakos P, De Souza A, Vazouras K, Gholami H, Pagni S, Weber HP. Survival rates of short dental implants $(\leq 6 \mathrm{~mm})$ compared with implants longer than 6 $\mathrm{mm}$ in posterior jaw areas: A meta-analysis. Clin Oral Implants Res 2018;29:8-20.

21. Himmlova L, Kácovský A, Konvičková S. Influence of implant length and diameter on stress distribution: a finite element analysis. J Prosthet Dent 2004;91(1):20-5

22. Petrie CS, Williams JL. Comparative evaluation of implant designs: influence of diameter, length, and taper on strains in the alveolar crest: A three-dimensional finite-element analysis. Clin Oral Implants Res. 2005;16(4):486-94.

23. Renouard F, Nisand D. Impact of implant length and diameter on survival rates. Clin Oral Implants Res 2006; 17:35-51.

24. Hämmerle $\mathrm{CH}$, Jung RE. Bone augmentation by means of barrier membranes. J Periodontol. 2000 2003;33(1):36-53.

25. Jovanovic SA, Spiekermann H, Richter EJ. Bone regeneration around titanium dental implants in dehisced defect sites: a clinical study. Int J Oral Maxillofac Implants. 1992;7(2).

26. Carmagnola D, Berglundh T, Araujo M, Albrektsson T, Lindhe J. Bone healing around implants placed in a jaw defect augmented with Bio-Oss $®$ : An experimental study in dogs. J Clin Periodontol 2000;27(11):799-805.

27. Cochran DL, Douglas HB. Augmentation of osseous tissue around non-submerged endosseous dental implants. Int J Periodontics Restorative Dent 1993, 13(6).

28. Wang HL, Boyapati L. "PASS" principles for predictable bone regeneration. Implant Dent 2006;15(1):8-17.

29. Her S, Kang T, Fien MJ. Titanium mesh as an alternative to a membrane for ridge augmentation. J Oral Maxillofac
Surg 2012;70(4):803-10. 